\title{
SEPARAÇÃO E QUANTIFICAÇÃO DE RIBOFLAVINA EM LEITE DESNATADO UAT POR UHPLC-FL
}

\author{
T. A. BECKER-ALGERI ${ }^{1}$, P. T. SCAGLIONI ${ }^{1}$, D. A. DRUNKLER ${ }^{2}$, E. B. FURLON ${ }^{1}$ \\ ${ }^{1}$ Universidade Federal do Rio Grande \\ ${ }^{2}$ Universidade Tecnológica Federal do Paraná \\ E-mail para contato: taniabecker86@yahoo.com.br
}

\begin{abstract}
RESUMO - Esse estudo visou estabelecer as condições de separação e quantificação da riboflavina em amostras de leite ultra alta temperatura (UAT) desnatado. As análises foram realizadas por meio de extração ácida seguido de separação e quantificação por cromatografia líquida de ultra alta eficiência acoplado de detector de fluorescência (UHPLC-FL). Foram ainda testados a linearidade e a seletividade do método através da construção das curvas de calibração e de efeito de matriz, respectivamente. A riboflavina foi detectada em tempo de retenção (tr) de 6,35 minutos e ambas as curvas apresentaram coeficientes de determinação $\left(\mathrm{r}^{2}\right)$ acima de 0,99 , além de o método se apresentar seletivo, por isso o mesmo foi considerado eficaz para a determinação de riboflavina em amostras de leite UAT desnatado.
\end{abstract}

Palavras-chave: cromatografia, leite, vitamina

DOI: $10.5965 / 24473650312017006$

\section{INTRODUÇÃO}

A riboflavina, 7,8-dimetil-10-ribitil-isoaloxazina, é uma vitamina hidrossolúvel pertencente ao complexo vitamínico B2, apresenta coloração amarela e fluorescência. Sua liberação no organismo humano ocorre em meio ácido, quando o bolo alimentar chega ao estômago, liberando as coenzimas FAD (flavina adenina dinucleotídeo) e FMN (flavina mononucleotídeos) ligadas a proteínas (MACHADO, 2003; SOUZA et al., 2005). Está presente em diversos alimentos, dentre eles o leite e as vísceras, como fígado e rins, sendo que mais de um quarto das recomendações de ingestão de vitamina B2 é proveniente do leite e seus derivados. O leite e os produtos lácteos são alimentos de elevada importância nutricional, pois além da grande variedade de nutrientes disponíveis, são constituídos por proteínas de alto valor biológico, minerais e vitaminas A, D, B12 e riboflavina como principais compostos vitamínicos (POWERS, 2003).

A deficiência de riboflavina na dieta humana é caracterizada por glossite, queratose, dermatite e neutropenia. É endêmica em muitas regiões do mundo e em certas populações que apresentam baixas ingestões das suas principais fontes: fígado, leite e derivados, rim, carne, ovos, ostras, germe de trigo, nabos, beterraba e farelo de arroz (FANICETO et al., 2000; FRANCO, 2002; POWERS et al., 2003).

Por se tratar de composto fluorescente, a técnica mais utilizada para a determinação de 
riboflavina em alimentos é a cromatografia líquida de alta eficiência (UHPLC-FL). Além de apresentar alta sensibilidade, grande poder de resolução e velocidade de separação dos componentes de interesse,possibilita a determinação simultânea de várias vitaminas em uma mesma amostra (PAPADOYANNIS; TSIONI, SAMANIDOU, 1997).

Tendo em vista a importância nutricional do leite e de seu teor vitamínico frente à dieta humana, o objetivo deste trabalho foi determinar as condições de separação e quantificação de riboflavina em amostras de leite UAT desnatado.

\section{MATERIAL E MÉTODOS}

\subsection{Material}

$\underline{\text { Amostras }}$

Para o estabelecimento das condições de separação e quantificação da riboflavina foram utilizadas amostras de leite UAT desnatado adquiridas no comércio local da cidade de MedianeiraPR.

Padrões e reagentes

O padrão de riboflavina utilizado na construção da curva de calibração foi adquirido da Sigma Chemical Company®, (USA, 2013). Para o preparo das amostras foram utilizados os seguintes reagentes com grau de pureza para análise (P.A.): ácido tricloacético (TCA) Anidrol®; hidróxido de sódio $(\mathrm{NaOH})$ FMaia ${ }$, ácido acético Vetec® e água ultrapura Milli Q®. Para filtração das amostras foram usados papel de filtro livre de cinzas Nalgon ${ }^{\circledR}(3 \mu \mathrm{m}$ de porosidade); seringas descartáveis

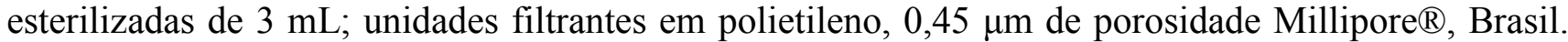
Para preparação das fases móveis foram utilizados metanol grau HPLC, J.T. Baker® e água ultrapura Milli Q®.

\subsection{Métodos}

Determinação da riboflavina por UHPLC-FL

Para a construção da curva de calibração, a solução padrão utilizada foi preparada a partir da diluição de $10 \mathrm{mg}$ de riboflavina em solução de ácido acético 0,02 N (sob proteção da luz), seguido de agitação em banho ultrassônico até total diluição, sendo o volume completado para $100 \mathrm{~mL}$, utilizando balão volumétrico (concentração teórica da solução estoque: $100 \mu \mathrm{g} \mathrm{mL}^{-1}$ ). A partir desta solução foi preparada a solução de trabalho, tomando-se para tanto uma alíquota de $1 \mathrm{~mL}$ da solução estoque e completado o volume para $10 \mathrm{~mL}$ com ácido acético $0,02 \mathrm{~N}$, utilizando balão volumétrico (concentração teórica $=10 \mu \mathrm{g} \mathrm{mL}^{-1}$ ). A partir desta solução, foram preparadas as demais soluções intermediárias para a construção da curva de calibração, constituídas pelas seguintes concentrações: $0,0001,0,001,0,01,0,05,0,1$ e $0,2 \mu \mathrm{gL}^{-1}$. Todas as soluções foram armazenadas em frasco âmbar sob proteção da luz.

Para a extração da riboflavina das amostras de leite UAT desnatado, foi utilizado o método proposto por Abranches, et al. (2008), o qual consiste na extração ácida da vitamina (TCA 16\%) por meio de agitação em banho ultrassônico $(1 \mathrm{~h})$ seguido de filtração e neutralização $(\mathrm{pH}$ 6,0 a 6,5) com $\mathrm{NaOH} 10 \%$ e nova purificação em unidades filtrantes de $0,45 \mu \mathrm{m}$ de porosidade. Todas as etapas foram realizadas em ambiente escuro, protegido da luz e em vidrarias âmbar, devido à 
fotossensibilidade do composto. Os extratos foram armazenados em frascos âmbar até quantificação em sistema UHPLC-FL.

As condições cromatográficas utilizadas foram: cromatógrafo líquido de ultra alta eficiência, Thermo Fisher Scientific ${ }^{\circ}$, munido de bomba quaternária de alta pressão, injetor automático termostatizado; detector de fluorescência; software "Chromeleon(c)" Dionex Versão 7.1.2.1478; coluna C18 Acclaim 120, $5 \mu \mathrm{m}$ Analítica (150 x 4,6 mm); fase móvel composta de metanol e água ultrapura (40:60); fluxo $1 \mathrm{~mL} / \mathrm{min}$. Os cromatogramas foram extraídos em comprimento de onda de excitação igual a $456 \mathrm{~nm}$ e de emissão igual a $525 \mathrm{~nm}$. As análises e pós-análises foram controladas por um computador acoplado ao sistema. A separação da riboflavina foi realizada por comparação do tempo de retenção do padrão e amostras analisadas sob as mesmas condições. Foram injetados $20 \mu \mathrm{L}$ de cada amostra, sendo o tempo de corrida de aproximadamente 10 minutos.

A curva de matriz foi obtida a partir da extração e quantificação da riboflavina presente em uma amostra de leite UAT desnatado. A partir deste extrato, foram obtidos os padrões com as seguintes concentrações: $0,0001,0,001,0,01,0,05,0,1$ e $0,2 \mu \mathrm{g} \mathrm{mL} \mathrm{m}^{-1}$.

\section{RESULTADOS E DISCUSSÃO}

O tempo de retenção (tr) da riboflavina foi comprovado a partir da injeção do padrão em concentrações crescentes (Figura 1), obtendo-se desta forma o tr de 6,353 minutos.

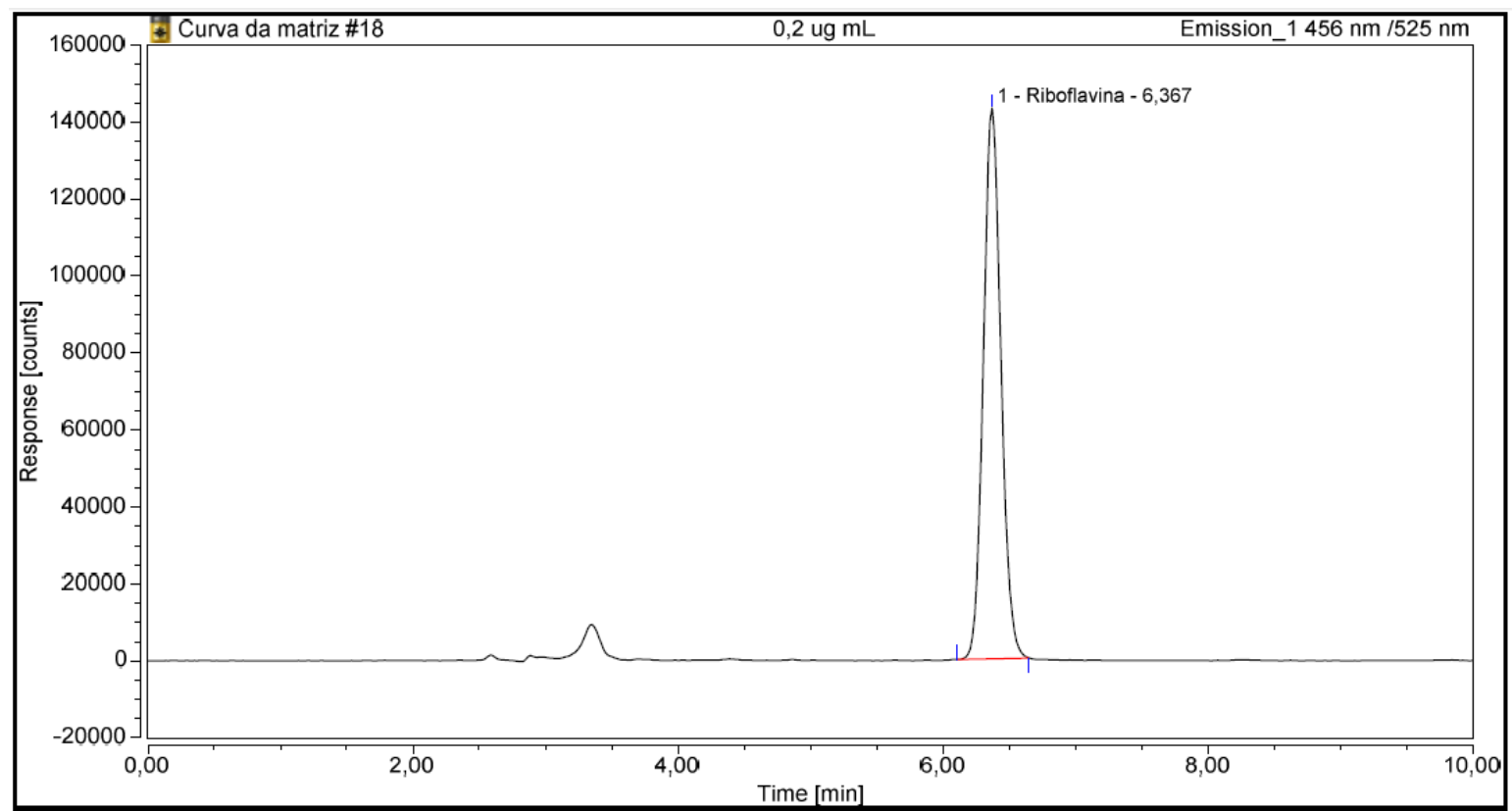

Figura 1: Cromatograma de confirmação do tempo de retenção da riboflavina (Concentração do padrão: $\left.0,2 \mu \mathrm{g} \mathrm{mL}^{-1}\right)$.

A partir da determinação do tr foi construída a curva de calibração da riboflavina. Os dados obtidos variando as concentrações do padrão foram ajustados em modelo de regressão linear para ser empregado na quantificação da vitamina em amostras de leite. $\mathrm{O}$ coeficiente de correlação $\left(\mathrm{r}^{2}\right)$ foi 
maior que 0,99, estando de acordo com orientações da ANVISA e do INMETRO, que recomendam,

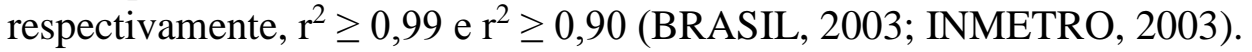

Após obtenção da curva de calibração, uma amostra de leite UAT desnatado foi submetida à extração em triplicata da vitamina. $\mathrm{O}$ extrato foi quantificado e apresentou teor de $0,53 \mu \mathrm{g} \mathrm{mL}^{-1}$. A partir deste extrato foram obtidos os pontos referentes à curva de efeito de matriz, a fim de garantir a seletividade do método (BRASIL, 2003). Os dados de regressão linear gerados à partir da construção da curva de efeito de matriz e da curva do padrão estão apresentados na Tabela 1.

Tabela 1: Indicativos de eficiência das curvas padrão e de robustez

\begin{tabular}{ccc}
\hline Indicativos & Curva padrão & Curva robustez \\
\hline Concentrações $\left(\mu \mathrm{g} \cdot \mathrm{mL}^{-1}\right)$ & $0,0001-0,2$ & $0,0001-0,2$ \\
Coef. de determinação $\left(\mathrm{r}^{2}\right)$ & 0.99865 & 0.99999 \\
Equação & $\mathrm{y}=108,5496 \mathrm{x}-215,6050$ & $\mathrm{y}=110,1212 \mathrm{x}-8,4934$ \\
\hline
\end{tabular}

A seletividade foi confirmada a partir da relação entre os coeficientes angulares das duas curvas, que foi igual a 0,98, indicando valor próximo a 1,0, que de acordo com a literatura é um indicativo de ausência de interferentes que possam causar efeito no instrumento (KRUVE et al., 2009).

Estudos recentes avaliaram a concentração de vitaminas em amostras de leite e derivados a partir da técnica de cromatografia líquida. Abranches et al. (2003) avaliaram o teor de riboflavina em leite desnatado, iogurte e queijo tipo petit suisse, e obtiveram tempos de retenção de 3,59, 3,50 e 3,53 minutos, respectivamente. Woollard e Indyk (2002) estudaram um método rápido para separação e determinação de tiamina, riboflavina, piridoxina e niacinamida em fórmulas infantis a partir da cromatografia líquida e obtiveram um limite de detecção de $0,004 \mu \mathrm{g} \mathrm{mL}^{-1}$ para a riboflavina com tr de 2,2 minutos e regressão linear $y=334,030 x-0,370$.

\section{CONCLUSÃO}

A partir deste estudo foi possível estabelecer as condições de separação e quantificação da riboflavina em amostras de leite em sistema UHPLC-FL. O tr da vitamina em corrida cromatográfica foi de 6,35 minutos, o método apresentou seletividade e o coeficiente de correlação linear $\left(\mathrm{r}^{2}\right)$ de 0,999 comprovou a linearidade do sinal do instrumento para riboflavina.

\section{REFERÊNCIAS}

ABRANCHES, M. V.; et al. Conteúdo de riboflavina em leite e produtos lácteos e comparação com o valor anunciado no rótulo. Alim. Nutr., Araraquara, v.19, n.3, p.307-314, 2008.

BRASIL (2003) - Agência Nacional de Vigilância Sanitária. Resolução - RE n. 899, de 29 de maio de 2003. Guia para Validação de Métodos Analíticos e Bioanalíticos. Disponível em: <http://www.anvisa.gov.br/legis/resol/2003/re/899_03re.htm>. Acesso em: novembro 2014. 
FANICETO, C.; CANAES, L. S.; FATIBELlO-FILHO, O.; CAVAlHEIRO, C. C. S.Determinação espectrofotométrica de vitamina B2 (riboflavina) em formulações farmacêuticas empregando sistema de análises por injeção em fluxo. Quím. Nova, v. 23, n. 5, p. 637-640, 2000.

FRANCO, G. Tabela de composição química dos alimentos. 9.ed. São Paulo: Atheneu, 2002. $307 \mathrm{p}$.

INMETRO (2003) - Instituto Nacional de Metrologia, Normalização e Qualidade Industrial. Orientações sobre validação de métodos de ensaios químicos. DOQCGCRE- 008, 2003.

KRUVE, A.; LEITO, I.; HERODES, K. Combating matrix effects in LC/ESI/MS: The extrapolative dilution approach. Anal. Chim. Acta, v. 651, p. 75-80, 2009.

MACHADO, F.M.S. Estratégias de concorrência da indústria alimentícia e seus desdobramentos na dimensão nutricional. 2003. 200 f. Tese (Doutorado em Nutrição Humana Aplicada - PRONUT) - Faculdade de Ciências Farmacêuticas, Faculdade de Economia, Administração e Contabilidade, Faculdade de Saúde Pública, Universidade de São Paulo, 2003.

PAPADOYANNIS, I.; TSIONI, G.K.; SAMANIDOU, V.F. Simultaneous determination of nine water and fat soluble vitamins after SPE separation and RP-HPLC analysis in pharmaceutical preparations and biological fluids. J. Liq. Chrom. Rel. Technol., v. 20, n. 19, p. 3203-3231, 1997. 2003.

POWERS, H.J. Riboflavin (vitamin B2) and health. Am. J. Clin. Nutr., v. 77, p. 1352-1360,

SOUZA, A. C. S.; FERREIRA, C. V.; JUCÁ, M. B.; AOYAMA, H.; CAVAGIS, A. D. M.; PEPPELENBOSCH, M. P. Riboflavina: uma vitamina multifuncional. Quím. Nova, v. 28, n. 5, p. 887-891, 2005.

WOOLLARD, D. C.; INDYK, H. E. Rapid Determination of Thiamine, Riboflavin, Pyridoxine, and Niacinamide in Infant Formulas by Liquid Chromatography. J. AOAC Int., v. 85, n. 4, p. 945 951, 2002. 